\title{
The interconnection between burnout level and personal factors of health-workers
}

\author{
Irina Skirtach ${ }^{1,2}$, Svetlana Kuzenko ${ }^{2}$, and Evgenia Pokul ${ }^{2, *}$ \\ ${ }^{1}$ Don State Technical University, Gagarin Sq., 1, Rostov-on-Don, 344000, Russia \\ ${ }^{2}$ Southern Federal University, Bolshaya Sadovaya str., 105/42, Rostov-on-Don, 344006, Russia
}

\begin{abstract}
Currently, the characteristics of the emergence and course of burnout syndrome among medical staff working with cancer children are not studied enough. It seems relevant to consider the psychological features of oncological medical specialists as an important personal factor, a protector of burnout syndrome. The features (empathetic tendencies, personal and situational anxiety, neurotization, self-actualization) in health care professionals working with cancer children were investigated. The object of the study was medical workers specializing in the field of oncology (doctors: radiologists, chemotherapists, hematologists, coloproctologists, hepatologists, pediatric oncologists, transfusiologists, etc.) with various experience. Research base was R. M. Gorbacheva Research Institute of Pediatric Oncology, Hematology and Transplantology, St. Petersburg. The study revealed the interconnection between the level of emotional burnout syndrome and levels of empathy tendencies, neurotization and anxiety of medical professionals: health workers with a high degree of empathy have less predisposition to burnout. The interconnection between the expression of emotional burnout syndrome and the self-actualization of personality of medical professionals was also revealed: the lower level of self-actualization the doctors have, the more inklined to emotional burnout they are.
\end{abstract}

\section{Introduction}

Recently, there has been an increase of mortality because of cancer in Russia. This serious illness leads to an increase of psychological problems both of the patients themselves and of the medical staff treating these patients. Negative emotions gradually accumulate and manifest themselves in unwillingness to work, helplessness, depression, psychosomatic diseases [1].

In Russia, new cases of cancer both of adults and children are recorded annually. Every year, 20,000 children under the age of 17 are diagnosed oncology and not everyone can have a chance to recover. In the field of work with cancer patients, the processes of professional and emotional burnout are considered to be more aggravated because of the constant necessity for interpersonal interaction with patients and their relatives; continuous observing of the suffering of children [2-4]. So, N.L. Perevezentseva describes in her study (2015) that after having examined 34 respondents, it turned out that $69 \%$ of respondents had burnout

\footnotetext{
* Corresponding author: limpopo-is@yandex.ru
} 
syndrome. In the work of N.V. Govorin and E.A. Bodagova (2016), it was found out that $67 \%$ doctors of various specialties faced burnout [5-7].

Issues of emotional burnout in the professional sphere of medical workers were studied by such authors as: Ognerubov N.A. 2013; Knyazeva N.A. and others. 2014; Udalova T.Yu. et al. 2017; Govorin N.V. and Bodagova E.A. 2016; Ikorsky A.A. 2015; Perevezentseva N.L. 2015; Lazareva E.Yu. and Nikolaev E.L. 2013; Almadakova O. A., 2014; Dunn S., 2015; Raboch J., 2014; Shaw J., 2015, Montgomery A., 2014, etc.

Currently, the characteristics of the appearance and the process of burnout syndrome among medical staff working with cancer children are not studied a lot. Meanwhile, the study of burnout features of these specialists involves taking into account their psychological characteristics essential for the professional sphere.

L. A. Leshchinsky points out the following qualities of doctors: "interest in specialty, humanity, despite the hostility, the desire to do good, a sense of duty, the ability for mercy, responsiveness and love for people; ability to make patients trust, willingness to reduce suffering, calm, leniency towards patients, sociability, readiness for self-sacrifice, punctuality, responsibility for treatment results, desire to work on themselves in the profession, self-criticism, ability to treat patients consciously, developed perception ("clinical sniff," "clinical eye"), stable emotional sphere, ability not to give in to panic, neatness, high psychological culture, politeness and correctness to patients, optimism, ability to suppress the feeling of breeziness at the patient's bed "[8].

According to L. S. Chutko and N. V. Kozina, cognitive and motivational personality substructures and style specifics of behavior are affected by burnout to a greater extent. It was established that burnout affects not only the level of individual components of the cognitive and motivational sphere, but also aims at their structure [9].

N. E. Vodopyanova identifies such personal risk factors as: elements of authoritarianism and rigidity in relations; low self-esteem and self-respect; introversion tendency; emotional reactivity [10].

The central determinant in the field of medicine, where none can do without understanding the feelings of the patient is human empathy. Empathy in the field of medical work is not so much a formal perception of what was said as a deep understanding of the internal meaning, awareness of the patient's condition, expressed by all non-verbal means: intonation, pose and gestures [11].

Znakov V.V. believes that the necessary personal qualities of a medical worker are: empathy, authority, sincerity, dedication, humanity, decency, personal maturity, restraint, accuracy, high self-discipline, optimism, mindfulness, high emotional stability and sensorimotor development (correct, dexterous, harmonious movements). Conscientious medical worker contraindicated neglect, blackness, cynicism, indifference, temper, promiscuity, negligence, arrogance, acrimony [12-17].

The aim of the research is to study the interconnection of emotional burnout syndrome with different personal characteristics and work experience of medical professional working with cancer children.

During the theoretical study, the following hypothesis was considered: there might be an interconnection between the level of formation of emotional burnout syndrome in health workers with different professional experience and the expression of such personal characteristics of health workers as empathy, neurotization, anxiety and self-actualization.

\section{Materials and methods}

Research methods: theoretical analysis of psychological literature, psychodiagnostic methods. For statistical verification of hypotheses, qualitative and quantitative methods of data processing were used (Kolmogorov-Smirnov criterion; Pearson rank correlation 
coefficient; ANOVA single-factor dispersion analysis, post-hoc analysis of Fisher.). Computer data processing was carried out using Microsoft Excel, IBM SPSS Statistics 23.0, STATISTICA 12.

Research techniques: "Research on the level of empathy tendencies" (I. M. Yusupov); "Technique for diagnosing the level of neurotization" by L. I. Wasserman; "Scale for assessing the level of reactive and personal anxiety" (Ch.D. Spielberg, Yu. L. Khanin); "Methodology for diagnosing the level of emotional burnout" V.V. Boyko; "Diagnosis of personality self-actualization" in the adaptation of N.F. Kalina.

Stages of the study. At first, a methodological apparatus was selected and formulated: hypotheses, goals, tasks; methods and techniques of research were selected. Next, we determined the groups of respondents and arranged the empirical research. The study involved 55 men and women aged from 21 to 53 years. After this, quantitative indicators of the levels of emotional burnout syndrome and personal characteristics of medical professionals were identified, statistical and correlation analysis of data was carried out.

\section{Results}

1. We found that medical workers with high empathy had a lesser predisposition to burnout. The doctors who were highly anxious and emotionally unstable, on the contrary, were inclined to burnout to a greater extent.

2. Health workers who have work experience up to 10 years have reliably lower index of burnout than the general indicator, particularly the stress, resistance and exhaustion phases, the significance of the symptoms of "experiencing circumstances," "anxiety and depression," "expanding the sphere of emotion hiding," "emotional isolation" and "psychosomatic disorders," as well as personal anxiety (Table 1).

Table 1. The results of a correlation analysis of the interconnection between the expression of emotional burnout syndrome and levels of empathy tendencies, neurotization, and anxiety of healthcare professionals by Pearson correlation coefficient.

\begin{tabular}{|l|c|c|c|c|}
\hline & $\begin{array}{c}\text { Empathy } \\
\text { trends }\end{array}$ & $\begin{array}{c}\text { Situational } \\
\text { anxiety }\end{array}$ & $\begin{array}{c}\text { Personality } \\
\text { anxiety }\end{array}$ & Neurotization \\
\hline I. Tension phase & - & - & $\mathbf{0 . 5 4 4 * *}$ & - \\
\hline III. Depletion phase & $\mathbf{- 0 . 5 8 6 * *}$ & $\mathbf{0 . 6 4 4 * *}$ & - & - \\
\hline Emotional isolation & - & $0.537^{* *}$ & - & - \\
\hline Personal suspension & $-0.509^{* *}$ & $0.533^{* *}$ & - & - \\
\hline Burnout syndrome & $-0.515^{* *}$ & $0.589^{* *}$ & $0.535^{* *}$ & $0.514^{* *}$ \\
\hline
\end{tabular}

Correlation analysis shows that there are reliable direct connections between the phases of burnout syndrome and personal anxiety, and situational anxiety, especially in the phase of tension (personal anxiety) and exhaustion (situational anxiety) $(-0,544 * *)$. There are also reliable direct links between situational anxiety and the symptoms of the depletion phase, such as "emotional detachment" and "personal detachment" $(0.644 * *)$. A reliable inverse connection was revealed between empathy and the phase of exhaustion of emotional burnout, as well as between the symptom of this phase "personal isolation" $(-0.586 * *)$. Reliably direct connections were noted between the overall emotional burnout syndrome score and situational anxiety, personality anxiety, and neurotization, and reliably inverse links between the overall burnout score and empathy.

3. Health workers with more than 10 years of professional experience, have reliably lower self-actualization scales such as "orientation in time," "creativity," "autonomy," "contact" and "flexibility in communication" (Table 2).

During the analysis of the results of the correlation between the general burnout syndrome index and personality self-actualization, it was found that the correlation is significant with 
all scales at the $r \leq 0,01$ level, that is, the connection has high statistical significance. The correlation coefficient is negative over all scales, this means that if the level of selfactualization of health workers increases, the formation of emotional burnout decreases. As we can see at Table 2, reliable inverse connection was identified between the time orientation scale and the depletion phase, between the view of human nature and the phase of exhaustion, as well as the symptom of "personal isolation". The "creativity" scale correlates with the resistance phase and its symptom "expansion of the sphere of hiding emotions," and the depletion phase.

Table 2. The results of correlation analysis of the interconnection of burnout syndrome level and personal self-actualization of healthcare professionals by Pearson correlation coefficient.

\begin{tabular}{|c|c|c|c|c|c|c|c|c|}
\hline & 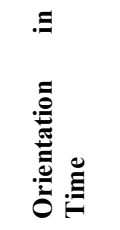 & 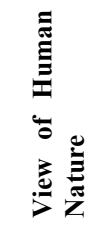 & 式 & 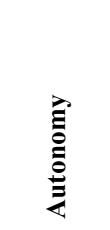 & 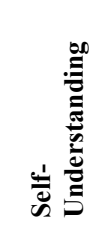 & 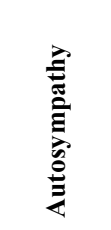 & 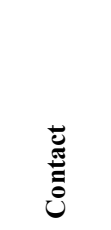 & 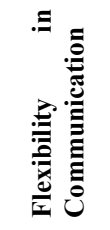 \\
\hline $\begin{array}{l}\text { I. Tension } \\
\text { phase }\end{array}$ & - & - & - & $-0.600 * *$ & $-0.633 * *$ & - & $-0.509 * *$ & - \\
\hline $\begin{array}{l}\text { Dissatisfaction } \\
\text { with oneself }\end{array}$ & - & - & - & - & - & - & $-0.528 * *$ & - \\
\hline $\begin{array}{l}\text { II. Resistance } \\
\text { Phase }\end{array}$ & - & - & $-0.543 * *$ & $-0.670 * *$ & $-0.512 * *$ & - & - & $-0.617 * *$ \\
\hline $\begin{array}{l}\text { Expansion of } \\
\text { emotion } \\
\text { saving }\end{array}$ & - & - & $-0.551^{* *}$ & $-0.691 * *$ & $-0.609 * *$ & $-0.513 * *$ & - & $-0.544 * *$ \\
\hline $\begin{array}{l}\text { III. Depletion } \\
\text { phase }\end{array}$ & $-0.574 * *$ & $-0.611 * *$ & $-0.622 * *$ & $-0.636^{* *}$ & $-0.610 * *$ & $-0.536 * *$ & - & $-0.691 * *$ \\
\hline $\begin{array}{l}\text { Personal } \\
\text { suspension }\end{array}$ & - & $-0.620 * *$ & - & $-0.601 * *$ & $-0.523 * *$ & - & - & $-0.661 * *$ \\
\hline CMEA & $-0.536^{* *}$ & $-0.559 * *$ & $-0.625^{* *}$ & $-0.766^{* *}$ & $-0.705^{* *}$ & $-0.583 * *$ & $-0.549^{* *}$ & $-0.705 * *$ \\
\hline
\end{tabular}

The greatest correlation is noted among the scales "flexibility in communication, "autonomy," "self-understanding." Correlation connections of autonomy and selfunderstanding coincide and are revealed between all three phases and such symptoms as: "dissatisfaction with oneself," "expansion of the sphere of saving emotions" and "personal exclusion." " Reliable inverse connections on the "flexibility in communication" scale was repeated by previous ones, the exception is the tension phase and the symptom "dissatisfaction with oneself." Inverse connection is also observed between contact, selfdissatisfaction and the tension phase, between autosympathy, the symptom "expansion of the hiding emotions sphere" and the phase of exhaustion. Thus, the lower the level of selfactualization doctors have, the more inclined to emotional burnout they are.

4. The development of emotional burnout syndrome directly depends on the length of working - the greater is the experience, the more remarkable is the emotional burnout syndrome. Health workers who have work experience up to 10 years are characterized by a sense of satisfaction with themselves and work, a slight appearance of "emotional indifference" at work, anticipation of future successes and the ability to enjoy current moments, they are creative, inspired to reveal their abilities, friendly, sociable and open.

5. Health workers who have more than 10 years of experience are characterized by prominent tiredness of communicating with colleagues and patients at work, lack of willingness to communicate even with family and friends, irritation and indignation because of work, exclusion of emotions from the professional area, thoughts about patients can cause poor mood, fear and exacerbation of chronic diseases. They are highly anxious, uncreative and unconfident and it is much harder for them to rely on their own strength. 
6. Medical workers rarely face the emotional burnout, if they enjoy the present moments of their lives and do not regret about the past, have an initially positive attitude to any person, a creative way of life and work, get used to rely on their own strength, openly express their feelings, are confident and able to establish strong, friendly relationships and disclose themselves.

\section{Theoretical and practical significance}

This work is devoted to the insufficiently studied topic of professional burnout of medical workers specializing in the field of oncology, working with children and its interconnection with their personal characteristics. As the researches we studied showed the problem of "emotional burnout" of oncologists is extremely relevant due to the specifics of their work. During the study, we managed to find out what the concept of "emotional burnout" implies; to determine what the specifics of work in the field of oncology are and how it affects the formation of burnout syndrome; to study the personal characteristics of doctors. The obtained data confirmed the hypothesis about the interconnection of the level of formation of emotional burnout syndrome and the personal characteristics of health workers, as well as the hypothesis that the level of formation of emotional burnout syndrome may differ among health workers with different professional experience. The work expands the already existing theoretical views on the problem of "burnout," as well as on understanding the general specifics of differences in the activities of medical workers with different experience specializing in the field of oncology

\section{Conclusion}

Further study of the topic of emotional burnout syndrome in health professionals working with cancer children is very relevant, since at present the psychological service for cancer patients is not sufficiently developed. The results of the study can be used to prepare programs for psychological prevention and correction of emotional burnout syndrome in medical professionals.

\section{References}

1. C. Maslach, M.P. Leiter, World Psychiatry 15, 104 (2016)

2. M. Skuratovskaya, E. Romanova, E3S Web of Conferences. EDP Sciences 210, 18096 (2020) https://doi.org/10.1051/e3sconf/202021018096

3. E. Suroedova, G. Uvarova, N. Shevkieva, E3S Web of Conferences 210, 19005 (2020) https://doi.org/10.1051/e3sconf/202021019005

4. C.E. Paiva, B.P. Martins, B.S.R. Paiva, BMC cancer 18(1), 1044 (2018) https://doi.org/10.1186/s12885-018-4964-7

5. N.V. Govorin, E.A. Bodagova, VSHOUZ bulletin 13 (2016)

6. I. Skirtach, N. Klimova, A. Dunayev, V. Korkhova, SHS Web of Conferences 70, 09009 (2019) https://doi.org/10.1051/shsconf/20197009011

7. T. Shanafelt, L. Dyrbye, Journal of Clinical Oncology 30(11), 1235-1241 (2012) https://doi.org/10.1200/JCO.2011.39.7380

8. L.A. Leshchinsky, Medical ethics and deontology (Piter, 2002)

9. L.S. Chutko, N.V. Kozina, Emotional burnout syndrome. Clinical and psychological aspects (MEDpress-inform, Moscow, 2014). 
10. N.E. Vodopyanova, Burnout syndrome (Peter Publishing House, 2007)

11. I. Skirtach, E. Pokul, E3S Web of Conferences 210, 17003 (2020) https://doi.org/10.1051/e3sconf/202021017003.

12. M. Clemons et al., Supportive Care in Cancer, 1-10 (2018) https://doi.org/10.1007/s00520-018-4567-5.

13. S. Kleiner, J.E. Wallace, BMC health services research 17(1), 639 (2017) https://doi.org/10.1186/s12913-017-2581-9

14. M. Kovacs, E. Kovacs, K. Hegedus, Psycho-Oncology 19(8), 855-862 (2010) https://doi.org/10.1002/pon.1631

15. S. Kumar, Healthcare. Multidisciplinary Digital Publishing Institute 4(3), 37 (2016) https://doi.org/10.3390/healthcare4030037

16. R. Ptacek, et al., Neuroendocrinol Lett 34(4), 259-264 (2013)

17. I. Skirtach, E. Denisova, V. Korkhova, E3S Web of Conferences 210, 17007 (2020) https://doi.org/10.1051/e3sconf/202021017007 